\title{
EFIKASI HERBISIDA AMETRIN UNTUK MENGENDALIKAN GULMA PADA PERTANAMAN TEBU (Saccharum officinarumL.) LAHAN KERING
}

\author{
Anggi Vidya Ningrum, Dad RJ Sembodo \& Rusdi Evizal \\ Jurusan Agroteknologi, Fakultas Pertanian, Universitas Lampung \\ Jl.Prof.Soemantri Brodjonegoro, No.1 Bandar Lampung 35145 \\ E-mail :anggividyaningrum@yahoo.co.id
}

\begin{abstract}
ABSTRAK
Dalam budidaya tebu salah satu masalah utama yang dihadapi adalah pengendalian gulma.Pengendalian gulma sejak awal pertanaman tebu merupakan upaya untuk menunjang pertumbuhan tanaman tebu.Fase kritis tanaman tebu terhadap gulma berlangsung selama tiga bulan awal pertumbuhan tebu.Pengaplikasian herbisida pratumbuh merupakan salah satu cara pengendalian guna menekan tingkat kompetisi tersebut.Tujuan penelitian (1) untuk mengetahui daya kendali herbisida ametrin terhadap pertumbuhan gulma golongan daun lebar dan rumput serta gulma dominan pada budidaya tebu lahan kering (2) pengaruh herbisida ametrin terhadap pertumbuhan tanaman tebu, dan (3) tingkat toksisitas herbisida ametrin terhadap tanaman tebu.Percobaan dilakukan di Desa Hajimena Kecamatan Natar Kabupaten Lampung Selatan dan Laboratorium Ilmu Gulma Fakultas Pertanian Universitas Lampung dari bulan Oktober 2012 sampai Januari 2013. Perlakuan terdiri dari ametrin 1,5 kg ha${ }^{1}$; ametrin 2,0 $\mathrm{kg} \mathrm{ha}^{-1}$; ametrin 2,5 $\mathrm{kg} \mathrm{ha}^{-1}$; ametrin $3,0 \mathrm{~kg} \mathrm{ha}^{-1}$; penyiangan mekanis; dan kontrol. Perlakuan diterapkan pada petak percobaan dalam rancangan acak kelompok (RAK).Setiap perlakuan diulang empat kali.Homogenitas ragam diuji dengan uji Bartlet dan aditivitas diuji dengan uji Tukey, selanjutnya data dianalisis dengan sidik ragam dan perbedaan nilai tengah diuji dengan Uji Beda Nyata Terkecil (BNT) pada taraf $5 \%$. Hasil penelitian menunjukkan bahwa (1) herbisida ametrin dosis 2,5 $\mathrm{k} \mathrm{kg} \mathrm{ha}^{-1}$ mampu menekan pertumbuhan gulma total dan daun lebar pada pertanaman tebu hingga 12 minggu setelah aplikasi (MSA), (2) pada 12 MSA perlakuan dosis 3,0 $\mathrm{kg} \mathrm{ha}^{-1}$ menghasilkan pertumbuhan tebu yang lebih baik dalam populasi dibandingkan penyiangan mekanis, dan (3) herbisida ametrin dengan dosis $1,5 \mathrm{~kg} \mathrm{ha}^{-1}$ hingga $3,0 \mathrm{~kg} \mathrm{ha}^{-1}$ tidak meracuni tanaman tebu.
\end{abstract}

Kata kunci : ametrin, gulma, tebu.

\section{PENDAHULUAN}

Salah satu hal yang berpengaruh dalam komponen produksi tanaman tebu adalah masalah gulma (Puspitasari et al., 2013). Menurut Indarto dan Sembodo (2002) gulma yang menjadi masalah utama pada perkebunan tebu antara lain Borreria alata, Mikania micrantha, Mimosa invisa, Dactyloctenium aegyptium, Panicum repens, dan Cyperus rotundus.Upaya pengendalian gulma yang dilakukan adalah secara kimiawi dengan menggunakan herbisida. Menurut Indarto dkk.(2003) pada budidaya tebu, herbisida yang banyak digunakan adalah herbisida pratumbuh. Penyemprotan herbisida pratumbuh dilakukan sebelum gulma, tanaman, atau keduanya tumbuh. Penyemprotan dilakukan dengan harapan tebu yang masih kecil dapat berkembang dengan maksimal tanpa adanya gangguan gulma.

Salah satu herbisida yang digunakan pada pertanaman tebu adalah ametrin. Ametrin merupakan herbisida yang sistemik dan selektif. Herbisida ini diabsorbsi oleh akar dan daun yang ditranslokasikan secara akropetal di dalam xilem serta terakumulasi dalam meristem pucuk. Herbisida ametrin telah lama digunakan pada pertanaman tebu (Tomlin, 2009). Meskipun ametrin telah lama digunakan pada budidaya tebu, pembuatan formulasi baru masih terus dilakukan oleh formulator pestisida. Sebelum herbisida dengan formulasi baru ini layak dipasarkan maka perlu dilakukan pengujian.

Adapun tujuan penelitian ialah untuk mengetahui daya kendali herbisida ametrin terhadap pertumbuhan gulma pada budidaya tebu lahan kering, pengaruh herbisida ametrin terhadap pertumbuhan tanaman tebu dan tingkat toksisitas herbisida ametrin terhadap tanaman tebu.

\section{BAHAN DAN METODE}

Penelitian dilaksanakan di Desa Hajimena, Kecamatan Natar, Provinsi Lampung dan Laboratorium Ilmu Gulma, Fakultas Pertanian, Universitas Lampung pada bulan Oktober 2012 sampai Januari 2013.Bahan yang digunakan adalah tebu varietas RGM 97-10120, 
pupuk NPK Phonska 15:15:15 dosis $300 \mathrm{~kg} \mathrm{ha}^{-1}$, Urea dosis $100 \mathrm{~kg} \mathrm{ha}^{-1}$, dan herbisida Ametrex $500 \mathrm{SC}$ (bahan aktif ametrin). Alat yang digunakan dalam penelitian ini adalah knapsack sprayer, nozzle merah,kuadran $0,5 \mathrm{~m} \times 0,5 \mathrm{~m}$.

Penelitian dilaksanakan dalam Rancangan Acak Kelompok (RAK) dengan 4 ulangan dan 6 perlakuan (Tabel 1). Setiap petak percobaan pada penelitian ini berukuran $5 \mathrm{~m}$ x $10 \mathrm{~m}$ dengan jarak antar petak $0,75 \mathrm{~m}$. Bibit tebu ditanam di alur menggunakan bahan tanam setek dua mata tunas. Pemupukan dilakukan bersamaan pada saat bibit tebu ditanam. Aplikasi herbisida dilakukan dengan menggunakan knapsack sprayer setelah pengolahan lahan dan pada saat dua hari setelah setek tebu ditanam. Volume semprot yang dihasilkan sebesar $400 \mathrm{l} / \mathrm{ha}$. Penyiangan mekanis dilakukan pada saat 4 dan 8 minggu setelah aplikasi (MSA). Pengambilan sampel gulma dilakukan sebanyak 3 kali pada 4, 8, dan 12 MSA. Gulma diambil dengan menggunakan kuadran berukuran $0,5 \mathrm{~m}$ x 0,5 m pada titik pengambilan sampel dengan masing-masing 2 kuadran per unit percobaan. Data di analisis dengan ANOVA. Kemudian dilanjutkan dengan perbedaan nilai tengah perlakuan dengan uji BNT pada taraf $5 \%$.

Variabel yang diamati ialah bobot kering gulma total, populasi dan tinggi tanaman, dan fitotoksisitas. Bobot kering golongan daun lebar dan gulma rumput. Gulma pada petak contoh yang masih segar dipotong tepat pada permukaan tanah kemudian dipilah-pilah menurut spesiesnya kemudian dioven dengan suhu $80^{\circ}$ selama 48 jam dan ditimbang bobot kering gulma. Data bobot kering gulma ini digunakan untuk menilai efikasi herbisida ametrin terhadap pertumbuhan gulma total, gulma tiap golongan, dan gulma dominan.

Populasi tanaman diamati pada 4, 8, dan 12 MSA. Pengamatan populasi dilakukan dengan menghitung tanaman tebu pada 3 baris tengah petak percobaan seluas $30 \mathrm{~m}^{2}$. Pengamatan tinggi tanaman dilakukan pada 4, 8, dan 12 MSA dengan cara mengukur tinggi tanaman dari permukaan tanah hingga daun terpanjang. Sampel tanaman adalah yang terletak pada tiga barisan tengah tanaman sebanyak 10 tanaman per satuan petak percobaan.

Daya racun herbisida terhadap tanaman diamati secara visual pada 4,8, dan 12 MSA dan ditentukan penilaian sebagai berikut :

0 : tidak ada keracunan ; $0-5 \%$ bentuk dan atau warna daun tidak normal

1 : keracunan ringan ; > $5-10 \%$ bentuk dan atau warna daun tidak normal

2 : keracunan sedang ; > $10-50 \%$ bentuk dan atau warna daun tidak normal

3 : keracunan berat ; > 50 - 75\% bentuk dan atau warna daun tidak normal

4 : keracunan sangat berat ; > $75 \%$ bentuk dan atau warna daun tidak normal

\section{HASIL DAN PEMBAHASAN}

Dari hasil penelitian pada 4 MSA perlakuan ametrin mampu menekan bobot kering gulma total sebesar 76-94\% (Gambar 1). Hal ini menunjukkan bahwa herbisida ametrin mampu mengendalikan pertumbuhan gulma.Pada 8 MSA, perlakuan ametrin dosis tertinggi $3,0 \mathrm{~kg} \mathrm{ha}^{-1}$ masih mampu menekan pertumbuhan gulma total dengan daya tekan sebesar $67 \%$ (Gambar 1). Hal ini sesuai Moenandir (1990) yang menyatakan bahwa semakin tinggi konsentrasi herbisida yang diterima oleh gulma maka akan meningkatkan penekanan herbisida terhadap pertumbuhan gulma. Pada 12 MSA, perlakuan ametrin dosis $2,0 \mathrm{~kg} \mathrm{ha}^{-1} \mathrm{dan} 2,5 \mathrm{~kg}$ ha $^{-1}$ yang mampu menekan pertumbuhan gulma total (Tabel 2). Hal ini kemungkinan dikarenakan gulma awal pada petak percobaan mampu ditekan sehingga tersedia ruang tumbuh lebih cepat untuk gulma baru. Contoh gulma baru yang mendominasi pada petak percobaan yaitu Celosia argentea. Munculnya gulma ini dikarenakan adanya suksesi, yaitu pergeseran atau perbedaan komposisi jenis gulma dibandingkan dengan kontrol. Menurut Utomo dan Wiroatmodjo (1981) dalam Tjitrosoedirdjo et al.(1984) apabila suatu populasi awal ada yang kita musnahkan, biasanya kesempatan untuk

Tabel 1. Perlakuan herbisida ametrin

\begin{tabular}{cccc}
\hline No & Perlakuan & Dosis Formulasi $(1 / \mathrm{ha})$ & Dosis Bahan Aktif $\left(\mathrm{kg} \mathrm{ha}^{-1}\right)$ \\
\hline 1 & Ametrin & 3,00 & 1,50 \\
2 & Ametrin & 4,00 & 2,00 \\
3 & Ametrin & 5,00 & 2,50 \\
4 & Ametrin & 6,00 & 3,00 \\
5 & Penyiangan mekanis & - & - \\
6 & Kontrol & - & - \\
\hline
\end{tabular}




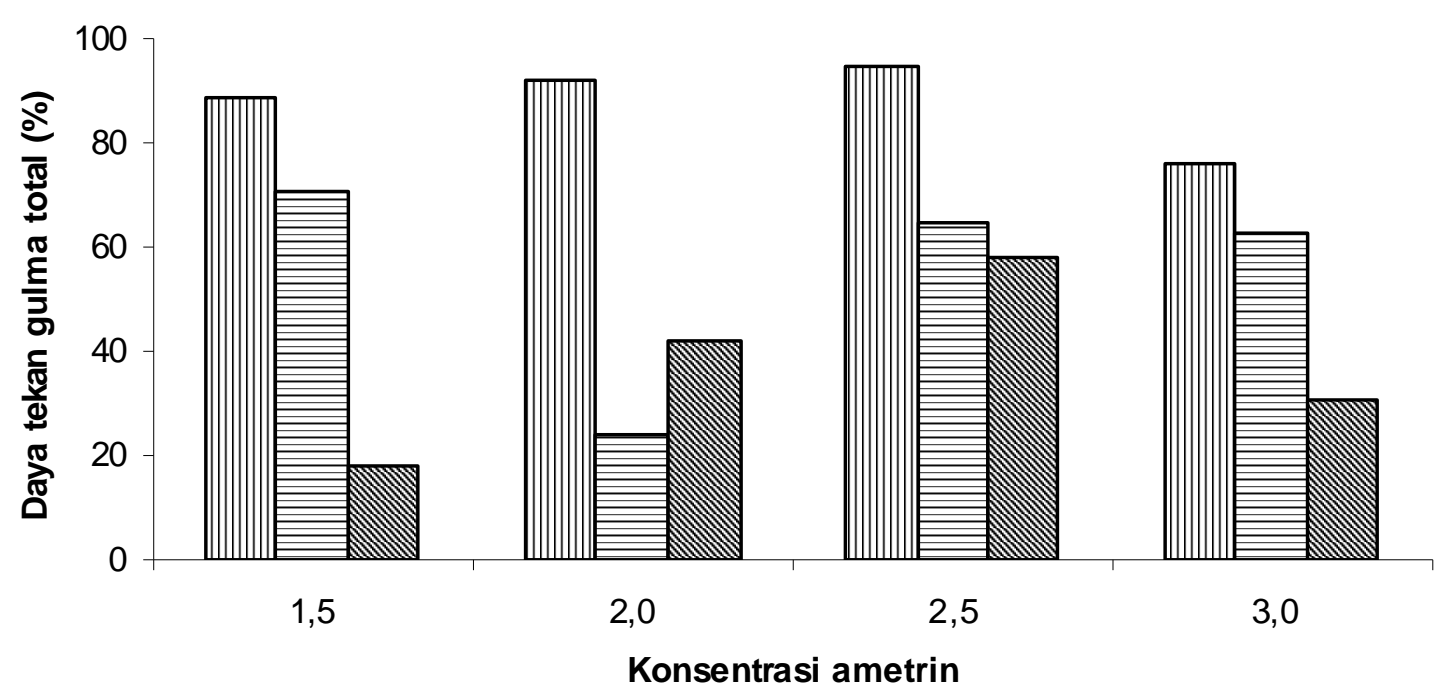

Gambar 1. Daya tekan gulma total (\%). 四=4 MSA, $\mathbf{\theta = 8}$ MSA, $\mathbb{\mathbb { N } = 1 2}$ MSA.

Tabel 2. Bobot kering gulma total $\left(\mathrm{g} / 0,5 \mathrm{~m}^{2}\right)$

\begin{tabular}{|c|c|c|c|c|c|c|c|c|c|c|}
\hline \multirow{3}{*}{$\begin{array}{l}\text { No } \\
1\end{array}$} & \multirow{2}{*}{\multicolumn{2}{|c|}{ Perlakuan }} & \multicolumn{3}{|c|}{4 MSA } & \multicolumn{3}{|c|}{8 MS A } & \multirow{2}{*}{\multicolumn{2}{|c|}{$\frac{12 \text { MS A }}{\text { Asli }}$}} \\
\hline & & & \multirow{2}{*}{$\frac{\text { Asli }}{0,80}$} & \multicolumn{2}{|c|}{$\begin{array}{c}\text { trans } \\
\sqrt{ } \sqrt{ }(\mathrm{x}+0,5)\end{array}$} & \multirow{2}{*}{$\frac{\text { Asli }}{46,77}$} & \multicolumn{2}{|c|}{$\begin{array}{c}\text { trans } \\
\sqrt{(x+0,5)}\end{array}$} & & \\
\hline & Ametrin & $1,5 \mathrm{~kg} \mathrm{ha}^{-1}$ & & 1,04 & $\mathrm{~b}$ & & 6,41 & $\mathrm{bc}$ & 172,29 & $a b$ \\
\hline 2 & Ametrin & $2,0 \mathrm{~kg} \mathrm{ha}^{-1}$ & 0,46 & 0,98 & $\mathrm{~b}$ & 89,88 & 9,25 & $a b$ & 117,66 & $\mathrm{bc}$ \\
\hline 3 & Ametrin & $2,5 \mathrm{~kg} \mathrm{ha}^{-1}$ & 0,44 & 0,96 & $\mathrm{~b}$ & 46,76 & 6,17 & $\mathrm{bc}$ & 83,83 & $\mathrm{~cd}$ \\
\hline 4 & Ametrin & $3,0 \mathrm{~kg} \mathrm{ha}^{-1}$ & 1,66 & 1,14 & $\mathrm{~b}$ & 57,22 & 7,28 & $\mathrm{bc}$ & 128,24 & $a b c$ \\
\hline 5 & Penyianga & mekanis - & 10,53 & 1,82 & $\mathrm{a}$ & 14,62 & 3,88 & c & 6,36 & $\mathrm{~d}$ \\
\hline \multirow[t]{2}{*}{6} & Kontrol & & 6,99 & 1,58 & $\mathrm{a}$ & 172,78 & 13,00 & $\mathrm{a}$ & 210 & $\mathrm{a}$ \\
\hline & \multicolumn{2}{|c|}{ BNT 0,05} & \multicolumn{3}{|c|}{0,30} & \multicolumn{3}{|c|}{3,78} & 87,31 & \\
\hline
\end{tabular}

Keterangan: $\mathrm{MSA}=$ minggu setelah aplikasi; Nilai tengah pada setiap kolom yang diikuti oleh huruf yang sama tidak berbeda nyata menurut uji BNT pada taraf $5 \%$.

tumbuh (biasanya dari biji yang dorman) gulma baru akan tersedia.

Pada gulma golongan daun lebar terdapat 24 spesies yaitu Ipomoea triloba, Phyllanthus niruri, Mimosa invisa, Synedrella nodiflora,Cleome rutidospermae, Spigelia anthelmia, Euphorbia geniculata, Richardia brasiliensis, Croton hirtus, Celosia argentea, Commelina diffusa, Tridax procumbens, Porophyllum ruderale, Commelina benghalensis, Euphorbia hirta, Borreria laevis, Borreria alata, Asystasia gangetica, Arachis pintoi, Calapogonium mucunoides, Oxalis barrelieri, Mimosa pudica,dan Sida rhombifolia. Hasil pada 4 MSA menunjukkan bahwa seluruh perlakuan herbisida mampu menekan pertumbuhan gulma berdaun lebar pada petak percobaan daripada penyiangan mekanis dan tanpa penyiangan (Tabel 3). Perlakuan herbisida ametrin pada dosis 1,5 hingga 3,0 $\mathrm{kg} \mathrm{ha}^{-1}$ mampu menekan bobot kering gulma daun lebar sebesar 86 - 96\% (Gambar 2). Pada 8 MSA, seluruh perlakuan herbisida masih mampu menekan pertumbuhan gulma berdaun lebar dengan daya tekan antara 64 hingga 94\% (Gambar 2). Hal ini sesuai dengan pendapat Tomlin (2009) yang menyatakan bahwa herbisida ametrin dapat mengendalikan gulma golongan daun lebar. Perlakuan ametrin dosis $2,5 \mathrm{~kg}$ $\mathrm{ha}^{-1}$ dan perlakuan mekanis mampu menekan pertumbuhan gulma daun lebar hingga 12 MSA. Hal ini dikarenakan adanya suksesi dimana gulma yang teracuni telah mati sehingga tersedia ruang tumbuh untuk muncul gulma-gulma lain tumbuh baru baik gulma yang sama 


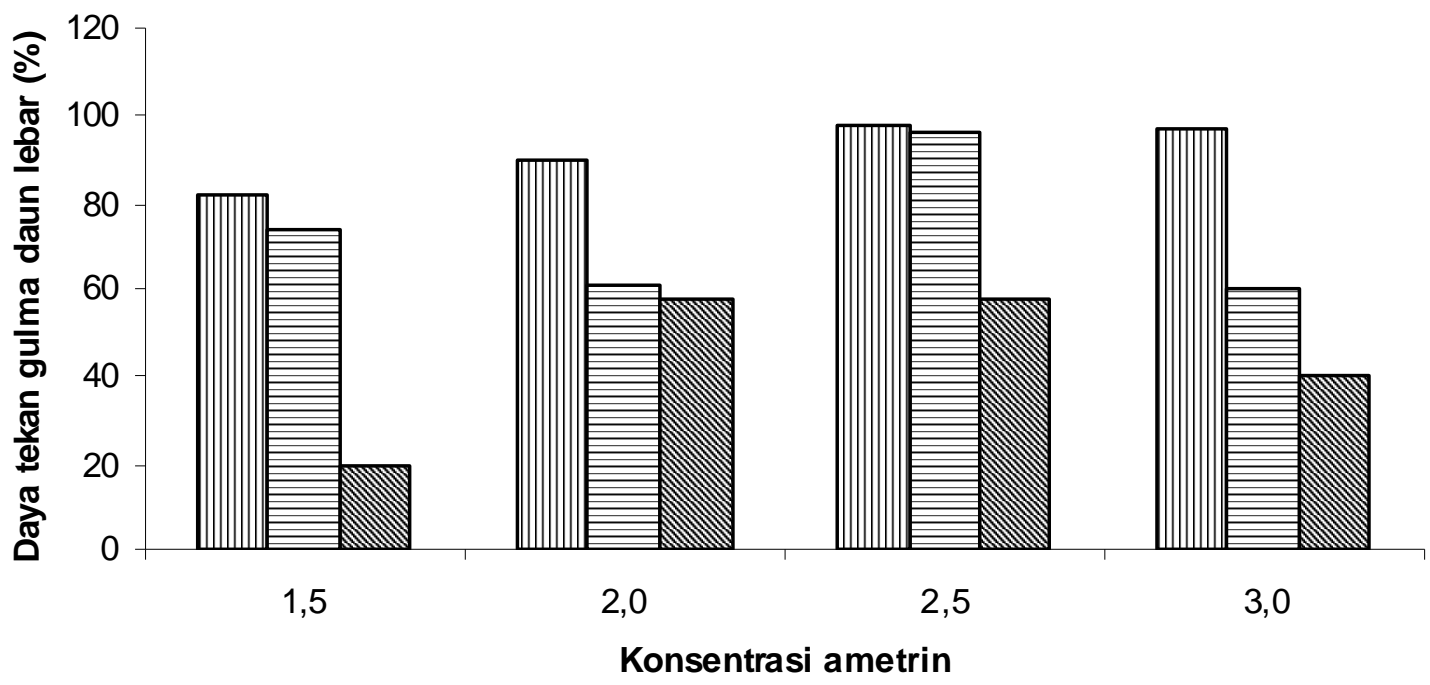

Gambar 2.Daya tekan gulma daun lebar (\%). $\mathbf{\square =} 4 \mathrm{MSA}, \boldsymbol{\theta}=8 \mathrm{MSA}, \mathbb{\mathbb { v }}=12 \mathrm{MSA}$.

Tabel 3. Bobot kering gulma daun lebar $\left(\mathrm{g} / 0,5 \mathrm{~m}^{2}\right)$

\begin{tabular}{|c|c|c|c|c|c|c|c|c|c|c|}
\hline \multirow{3}{*}{$\begin{array}{c}\text { No } \\
1\end{array}$} & \multirow{2}{*}{\multicolumn{2}{|c|}{ Perlakuan }} & \multicolumn{3}{|c|}{$4 \mathrm{MSA}$} & \multicolumn{3}{|c|}{$8 \mathrm{MSA}$} & \multicolumn{2}{|c|}{$12 \mathrm{MSA}$} \\
\hline & & & \multirow{2}{*}{$\begin{array}{c}\text { Asli } \\
0,70\end{array}$} & \multicolumn{2}{|c|}{$\begin{array}{c}\text { trans } \\
\sqrt{\sqrt{ }(\mathrm{x}+0,5)}\end{array}$} & \multirow{2}{*}{$\begin{array}{c}\text { Asli } \\
39,20\end{array}$} & \multicolumn{2}{|c|}{$\begin{array}{c}\text { trans } \\
\sqrt{(}(x+0,5)\end{array}$} & \multirow{2}{*}{$\begin{array}{c}\text { Asli } \\
151,73\end{array}$} & $\begin{array}{c}\text { trans } \\
\sqrt{(}(x+0,5)\end{array}$ \\
\hline & $1,5 \mathrm{~kg}$ ha & & & 1,01 & $\mathrm{~b}$ & & 5,74 & $\mathrm{bc}$ & & $11,29 \mathrm{ab}$ \\
\hline 2 & Ametrin & & 0,36 & 0,94 & $b$ & 48,37 & 6,76 & $\mathrm{~b}$ & 87,75 & 9,13 \\
\hline 3 & Ametrin & & 0,06 & 0,86 & $\mathrm{~b}$ & 8,93 & 2,96 & $\mathrm{c}$ & 80,46 & 8,22 \\
\hline 4 & Ametrin $\quad 3,0 \mathrm{~kg} \mathrm{ha}$ & & 0,22 & 0,91 & $\mathrm{~b}$ & 52,16 & 6,87 & $\mathrm{~b}$ & 111,23 & 10,52 \\
\hline 5 & Penyiangan mekanis & - & 7,91 & 1,68 & $\mathrm{a}$ & 8,44 & 2,87 & $\mathrm{c}$ & 5,78 & 2,10 \\
\hline 6 & Kontrol & - & 4,94 & 1,48 & $\mathrm{a}$ & 143,05 & 11,87 & $\mathrm{a}$ & 198,57 & 13,19 a \\
\hline \multicolumn{3}{|c|}{ BNT 0,05} & & 0,24 & & & 3,08 & & & 4,25 \\
\hline
\end{tabular}

Keterangan: $\mathrm{MSA}=$ minggu setelah aplikasi, Nilai tengah pada setiap kolom yang diikuti oleh huruf yang sama tidak berbeda nyata menurut uji BNT pada taraf $5 \%$.

maupun gulma daun lebar pada 8 MSA. Pada 12 MSA seluruh perlakuan herbisida ametrin mampu menekan pertumbuhan gulma daun lebar dengan daya tekan antara 24 hingga 59\% (Gambar 2).

Gulma golongan rumput pada petak percobaan sebanyak 6 spesies yaitu Dactyloctenium aegyptium, Paspalum commersonii, Echinochloa colonum, Eleusine indica, Brachiaria mutica, dan Rotboelia exaltata. Hasil pada 4 dan 8 MSA menunjukkan bahwa semua perlakuan tidak mampu menekan pertumbuhan gulma golongan rumput (Tabel 4).Hal ini diduga dikarenakan keselektifan seluruh herbisida yang diuji cenderung mampu mengendalikan gulma daun lebar daripada gulma golongan rumput.Pada $12 \mathrm{MSA}$, hanya perlakuan mekanis yang berbeda nyata dengan kontrol.
Menurut Tjitrosoedirjo et al. (1984) pengendalian mekanis merupakan cara yang umumnya berhasil baik untuk dilakukan pada berbagai jenis gulma setahun tetapi dalam kondisi tertentu juga efektif bagi gulma-gulma menahun.

Berdasarkan hasil pada Tabel 5, setiap pengamatan $(4,8$, dan $12 \mathrm{MSA})$ terlihat bahwa semua perlakuan yang dilakukan baik perlakuan herbisida maupun kontrol menunjukkan nilai yang tidak berbeda jika dibandingkan dengan perlakuan mekanis.Hal ini menunjukkan bahwa herbisida ametrin yang diaplikasikan pada dosis (1,5 hingga 3,0 $\left.\mathrm{kg} \mathrm{ha}^{-1}\right)$ tidak memberikan pengaruh negatif terhadap tinggi tanaman tebu. 
Tabel 4. Bobot kering gulma golongan rumput $\left(\mathrm{g} / 0,5 \mathrm{~m}^{2}\right)$

\begin{tabular}{|c|c|c|c|c|c|c|c|c|c|c|c|}
\hline \multirow{3}{*}{$\begin{array}{c}\text { No } \\
1\end{array}$} & \multirow{2}{*}{\multicolumn{2}{|c|}{ Perlakuan }} & \multicolumn{3}{|c|}{4 MSA } & \multicolumn{3}{|c|}{$8 \mathrm{MSA}$} & \multicolumn{3}{|c|}{$12 \mathrm{MS} \mathrm{A}$} \\
\hline & & & \multirow{2}{*}{$\begin{array}{c}\text { Asli } \\
0,10\end{array}$} & \multicolumn{2}{|c|}{$\begin{array}{c}\text { trans } \\
\sqrt{\sqrt{[}[(x+0,5)}\end{array}$} & \multirow{2}{*}{$\begin{array}{c}\text { As li } \\
6,50\end{array}$} & \multicolumn{2}{|c|}{$\begin{array}{l}\text { trans } \\
\sqrt{(x+0,5)}\end{array}$} & \multirow{2}{*}{$\begin{array}{c}\text { Asli } \\
32,97\end{array}$} & \multicolumn{2}{|c|}{$\begin{array}{c}\operatorname{trans} \\
\sqrt{\sqrt{\sqrt{ }}(\mathrm{x}+0,5)}\end{array}$} \\
\hline & Ametrin & $1,5 \mathrm{~kg} \mathrm{ha}^{-1}$ & & 0,94 & b & & 2,45 & $b$ & & 1,37 & $\mathrm{a}$ \\
\hline 2 & Ametrin & $2,0 \mathrm{~kg} \mathrm{ha}^{-1}$ & 0,11 & 0,94 & $\mathrm{~b}$ & 41,43 & 6,23 & $\mathrm{a}$ & 30,59 & 1,43 & a \\
\hline 3 & Ametrin & $2,5 \mathrm{~kg} \mathrm{ha}^{-1}$ & 0,38 & 0,97 & $a b$ & 37,18 & 5,20 & $a b$ & 4,49 & 1,22 & $a b$ \\
\hline 4 & Ametrin & $3,0 \mathrm{~kg} \mathrm{ha}^{-1}$ & 1,44 & 1,04 & $a b$ & 5,06 & 1,96 & $\mathrm{~b}$ & 13,00 & 1,25 & $a b$ \\
\hline 5 & Penyianga & mekanis - & 2,63 & 1,11 & $\mathrm{a}$ & 6,18 & 2,37 & $b$ & 0,57 & 0,98 & $\mathrm{~b}$ \\
\hline 6 & Kontrol & - & 2,05 & 1,05 & $a b$ & 29,74 & 4,60 & $a b$ & 22,57 & 1,47 & $\mathrm{a}$ \\
\hline \multicolumn{3}{|c|}{ BNT 0,05 } & \multicolumn{3}{|c|}{0,17} & \multicolumn{3}{|c|}{3,61} & \multicolumn{3}{|c|}{0,32} \\
\hline
\end{tabular}

Keterangan: $\mathrm{MSA}=$ minggu setelah aplikasi, Nilai tengah pada setiap kolom yang diikuti oleh huruf yang sama tidak berbeda nyata menurut uji BNT pada taraf $5 \%$.

Tabel 5. Tinggi tanaman tebu $(\mathrm{cm})$

\begin{tabular}{|c|c|c|c|c|c|c|c|c|c|c|}
\hline \multirow{3}{*}{$\begin{array}{c}\text { No } \\
1\end{array}$} & \multirow{2}{*}{\multicolumn{3}{|c|}{ Perlakuan }} & \multicolumn{3}{|c|}{$4 \mathrm{MSA}$} & \multirow{2}{*}{\multicolumn{2}{|c|}{$\frac{8 \mathrm{MSA}}{\mathrm{Asli}}$}} & \multirow{2}{*}{\multicolumn{2}{|c|}{$\frac{12 \mathrm{MSA}}{\text { Asli }}$}} \\
\hline & & & & \multirow{2}{*}{$\frac{\text { Asli }}{49,65}$} & \multicolumn{2}{|c|}{ trans $\sqrt{[}[(\mathrm{x}+0,5)$} & & & & \\
\hline & Ametrin & $1,5 \mathrm{~kg}$ & & & 1,63 & $\mathrm{a}$ & 113,78 & $\mathrm{~b}$ & 189,06 & $a b$ \\
\hline 2 & Ametrin & $2,0 \mathrm{~kg}$ & & 49,88 & 1,63 & a & 128,46 & $a b$ & 194,85 & $\mathrm{a}$ \\
\hline 3 & Ametrin & $2,5 \mathrm{~kg}$ & & 50,05 & 1,63 & $\mathrm{a}$ & 121,86 & $a b$ & 191,36 & $\mathrm{ab}$ \\
\hline 4 & Ametrin & $3,0 \mathrm{~kg}$ & & 52,88 & 1,64 & $\mathrm{a}$ & 134,91 & $\mathrm{a}$ & 203,57 & $\mathrm{a}$ \\
\hline 5 & Penyiang & nekanis & - & 49,03 & 1,63 & $\mathrm{a}$ & 117,81 & $\mathrm{~b}$ & 180,63 & $a b$ \\
\hline 6 & Kontrol & & - & 50,60 & 1,63 & $\mathrm{a}$ & 124,50 & $a b$ & 152,16 & $\mathrm{~b}$ \\
\hline & BNT 0,0 & & & & 0,04 & & 17,05 & & 40,45 & \\
\hline
\end{tabular}

Keterangan: $\mathrm{MSA}=$ minggu setelah aplikasi, Nilai tengah pada setiap kolom yang diikuti oleh huruf yang sama tidak berbeda nyata menurut uji BNT pada taraf $5 \%$.

Tabel 6. Populasi tanaman tebu ( batang/ $30 \mathrm{~m}^{2}$ )

\begin{tabular}{|c|c|c|c|c|c|c|c|}
\hline $\mathrm{NO}$ & \multicolumn{2}{|c|}{ Perlakuan } & $4 \mathrm{MSA}$ & \multicolumn{2}{|c|}{$8 \mathrm{MSA}$} & \multicolumn{2}{|c|}{$12 \mathrm{MSA}$} \\
\hline 1 & Ametrin & $1,5 \mathrm{~kg} \mathrm{ha}^{-1}$ & $94,00 \quad a b$ & 117,50 & $\mathrm{a}$ & 124,75 & $a b c$ \\
\hline 2 & Ametrin & $2,0 \mathrm{~kg} \mathrm{ha}^{-1}$ & $107,00 \mathrm{ab}$ & 124,25 & a & 135,25 & $\mathrm{abc}$ \\
\hline 3 & Ametrin & $2,5 \mathrm{~kg} \mathrm{ha}^{-1}$ & $105,50 \mathrm{ab}$ & 140,25 & $\mathrm{a}$ & 142,75 & $a b$ \\
\hline 4 & Ametrin & $3,0 \mathrm{~kg} \mathrm{ha}^{-1}$ & 121,25 & 160,50 & $\mathrm{a}$ & 167,75 & $\mathrm{a}$ \\
\hline 5 & Penyiang & mekanis - & $77,50 \quad a b$ & 106,75 & $a b$ & 116,25 & $\mathrm{bc}$ \\
\hline \multirow[t]{2}{*}{6} & Kontrol & - & $66,25 \quad b$ & 58,75 & $\mathrm{~b}$ & 93,75 & $\mathrm{c}$ \\
\hline & BNT 0,0 & & 45,61 & 54,44 & & 48,08 & \\
\hline
\end{tabular}

Keterangan: $\quad$ MSA= minggu setelah aplikasi, Nilai tengah pada setiap kolom yang diikuti oleh huruf yang sama tidak berbeda nyata menurut uji BNT pada taraf $5 \%$. 
Hasil pada Tabel 6 menunjukkan bahwa pada semua dosis ametrin tidak berbeda nyata dengan penyiangan mekanis pada pengamatan 4 dan 8 MSA.Hal ini sejalan dengan penelitian Alfredo et al.(2012) bahwa aplikasi herbisida ametrin tidak mempengaruhi populasi tanaman tebu.Sedangkan pada 12 MSA dosis ametrin $3,0 \mathrm{~kg} \mathrm{ha}^{-1}$ memiliki nilai berbeda dengan penyiangan mekanis. Hal ini berarti ametrin dengan dosis $3,0 \mathrm{~kg}$ $\mathrm{ha}^{-1}$ mengakibatkan gulma tertekan pertumbuhannya sehingga menghasilkan pertumbuhan tebu dengan populasi yang tinggi dibandingkan penyiangan mekanis.Sedangkan perlakuan tanpa penyiangan gulma (kontrol) menghasilkan populasi yang rendah karena mata tunas tidak berkecambah dan tunas mengalami kematian.

Selama penelitian ini berlangsung tidak ditemukan adanya gejala fitotoksisitas pada 4, 8, dan 12 MSA.Hal ini sejalan dengan data pengamatan tinggi dan populasi tanaman yang menunjukkan herbisida ametrin tidak mempengaruhi pertumbuhan dan pembentukan anakan tanaman tebu.

\section{KESIMPULAN}

Herbisida ametrin dosis $2,5 \mathrm{~kg} \mathrm{ha}^{-1}$ mampu menekan pertumbuhan gulma total dan daun lebar pada pertanaman tebu hingga 12 minggu setelah aplikasi (MSA). Pada 12 MSA perlakuan dosis $3,0 \mathrm{~kg} \mathrm{ha}^{1}$ menghasilkan pertumbuhan tebu yang lebih baik dalam populasi dibandingkan penyiangan mekanis. Herbisida ametrin dengan dosis $1,5 \mathrm{~kg} \mathrm{ha}^{-1}$ hingga $3,0 \mathrm{~kg} \mathrm{ha}^{-1}$ tidak meracuni tanaman tebu.

\section{DAFTAR PUSTAKA}

Alfredo, N., N. Sriyani, dan D.R.J.Sembodo. 2012. Efikasi Herbisida Pratumbuh Metil Metsulfuron Tunggal dan Kombinasinya dengan 2,4-D, Ametrin, dan Diuron Terhadap Gulma Pada Pertanaman Tebu (Saccharum officinarum L.) Lahan Kering. Jurnal Agrotropika.17(1): 29-34.

Indarto danD.R.J, Sembodo. 2002. Aplikasi herbisida patumbuh pada tiga varietas tebu (Saccharum officinarum L.).Jurnal Agrotropika.7(1): 4-9.

Indarto, D.R.J, Sembodo, dan D.Mawardi. 2003. Aplikasi metribuzin (sencor 480 SC) sebagai herbisida pratumbuh pada pertanaman tebu lahan kering. Prosiding Simposium Nasional dan Kongres PERAGI VII.Hal.297-301.

Moenandir.1990. Fisiologi Herbisida. Jakarta. Rajawali Press. 139 hal.

Tjitrosoedirdjo, S., I.H. Utomo dan J. Wiroatmodjo ( Eds). 1984. Pengelolaan

Gulma di Perkebunan. Kerjasama Biotrop Bogor PT. Gramedia. Jakarta. 225 hal.

Tomlin, C.D.S. 2009.ThePesticides Manual version 5.0 (fifthteen edition).British Crop Protection Council.Hal 589.

Puspitasari, K., H.T. Sebayang, dan B.Guritno. 2013. Pengaruh Aplikasi Herbisida Ametrin dan 2,4 $D$ dalam Mengendalikan Gulma Tanaman Tebu (Saccharum officinarum L.). Jurnal Produksi Tanaman. 1(2):72-80. 